\title{
English as a lingua franca in aviation ${ }^{1}$
}

\author{
WALTER SEILER
}

The International Civil Aviation Organization now requires

all airline pilots to have at least a basic command of conversational English, but Walter Seiler is concerned that an over-emphasis on native-speaker varieties might lead to even more misunderstandings

\section{Introduction}

The story of the unparalleled spread of the English language around the world has been told many times (e.g. Crystal, 2004). English gained its status as the world's most important language of science, business and tourism in the 20th century and as early as 1950 it was made the official language of aviation (Tajima, 2004:453). As aviation communication is highstakes with lives depending on it, it should ideally be free of vagueness and ambiguities. However, as is well-known, human languages do not function like the languages of logic or mathematics. To illustrate this with just one example, double negatives do not necessarily yield a positive ('you ain't seen nothing yet'). In fact, in contrast to artificial languages, natural languages are often characterised by vagueness, misunderstandings and ambiguities. Indeed, the potential for misunderstandings has been called a defining feature of human language: 'indeterminateness is (...) the first law of language, as it is one of the conditions of meaningful communication. One of the ideals of language is that its signs shall be mobile enough "to express any number of meanings with equal ease." (...) For language to represent or symbolize reality, it must be fluid enough to express newly discovered aspects of being. To use language meaningfully, therefore, in one sense of the word at least, requires that it shall be used ambiguously, that words shall have many voices' (Urban, 1939:192). ${ }^{2}$
Misunderstandings occur at every level of language, phonetic decoding may fail (mishearing), words may be wrongly interpreted (lexical ambiguity such as in 'knock up'), syntactic structure may be ambiguous (e.g. 'visiting relatives can be boring') and speaker intention may be missed ("Can I get you anything else?" interpreted as a genuine question, rather than as a hint that it is time to go home at the end of long dinner party). Such misunderstandings occur between speakers of the same language variety who share the same socio-cultural background. Obviously, when it comes to verbal interaction between speakers from vastly different backgrounds who use a shared second language for communication, misunderstandings are even more likely to occur. If lives depend on successful communication such as is the case in aviation, it is paramount that all possible measures be taken to avoid such misunderstandings.

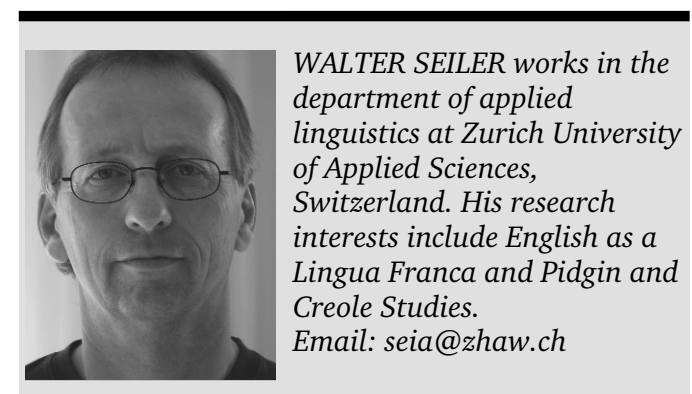




\section{Aviation English}

In order to minimise fatal miscommunication in aviation, an attempt was made to handle predictable standard situations by means of a set of phrases with clearly defined meanings. In the latest edition of its manual of radiotelephony ICAO (International Civil Aviation Organization) states that phraseologies are developed to provide 'efficient, clear, concise, and unambiguous communications' (International Civil Aviation Organization, 2007). ${ }^{3}$ While the introduction of phraseologies may have led to an improvement in aviation communication, it clearly has not led to a situation where misunderstandings have been stamped out. It is in fact on this basis that the choice of English as the lingua franca in aviation has been severely criticised. Thus, Jones (2003) argues that seemingly unambiguous phraseology has utterly failed to produce sufficient clarity in communication. He cites multiple meaning of words ('gate', 'taxi') and phrases, homonyms ('break'/'brake'), illogical expressions (such as 'stop and go', where the interpretation of 'and' is sequential and not simultaneous) among other things in support of his claim. Jones concludes by stating that 'the inability of English to express specific instructions to pilots without confusion would seem to disqualify it as a language for permanent use by aviation.' (Jones, 2003:244). While fundamental criticism of the suitability of English (or indeed any other natural language) as an international language for aviation may be justified, it is in fact clear that English has now been accepted world-wide, and attempts to displace it appear misguided. What the international community needs to concentrate on is rather the question of how the quality of communication through English can be improved. One such attempt was made by Tajima (2004), who provides a detailed examination of a number of fatal accidents and the nature of miscommunication that led to these accidents. Misunderstandings include the use of inappropriately colloquial language between L1 speakers, syntactic ambiguities (the famous Tenerife disaster, which was due to different interpretations of the phrase 'at take-off, i.e. waiting for take-off or in the process of taking off (Tajima, 2004:459)) and insufficient command of English or incomprehensible English. The author goes on to give a number of recommendations how miscommu- nication in air traffic could be minimised, including language training for L2 as well as L1 English speakers.

\section{The need for Plain English}

Given the number of accidents due to miscommunication still occurring despite fixed phraseology, it was realised that more needed to be done to deal with emergency situations which require linguistic skills that go beyond a set of phrases designed to cope with routine tasks. 'According to ICAO statistics, between 1976 and 2001, more than 1,100 airline passengers and crew lost their lives in accidents in which communications played a significant role. Numerous other incidents involving the misuse or lack of understanding of English continue to be reported annually' (Considine, 2007). For a recent case of a fatal accident which was blamed on poor English see The Sunday Morning Herald (2008).

ICAO therefore stipulated that operating at an international level necessitates basic English competence for pilots and controllers. For six language areas (pronunciation, structure, vocabulary, fluency, comprehension, interaction) holistic descriptors were defined which describe competence levels ranging from expert (level 6) to pre-elementary (level 1). Level 4 is defined as operational, i.e. the minimum level of proficiency.

Operational level 4 English proficiency as a prerequisite for licensing purposes was introduced in March 2008 (International Civil Aviation Organization, 2004; 2008). ICAO leaves it to its member states to implement the new regulation and does not itself develop a test to measure proficiency.

While moves to increase aviation safety by stipulating minimum levels of English competency are clearly welcome, two important issues have so far not been addressed in the relevant literature. The first question concerns the language raters: who decides whether a candidate's English meets the minimum requirement? The second - more fundamental - question touches on the problem of the internal diversity of English. This language is used around the world in many different varieties, some of which are mutually unintelligible. Which varieties are acceptable in international aviation? I will briefly deal with the first question and then discuss the second one in some detail. 


\section{The language raters}

Traditionally, in language testing the situation is one where native-speaker raters judge nonnative speakers' performance. Top marks are awarded to those speakers whose performance is near native-like. For example, an examinee's pronunciation or accent is assessed on the basis of the extent to which it is understandable or intelligible to the rater. This may be appropriate in a situation where learners acquire a language to talk to L1 speakers of the language. However, for English the situation has changed radically. English is now widely used for communication between non-native speakers and while exact figures are hard to come by, it is clear that a considerable amount of what is said and written in English today does not involve any L1-English speakers. In international tourism, for example, where English is the primary means of communication, nearly $75 \%$ of all journeys are made from a non-English speaking country to a non-English speaking country (Graddol, 2006:29). A similar scenario obtains for aviation, where a large percentage of communication done through the medium of English is carried out between L2-English speakers. Successful communication through the medium of English between say - an Italian controller and a Pakistani pilot does not depend on an English L1 speaker's assessment of the intelligibility of the English used by the Italian and the Pakistani. What matters is that they are intelligible to each other. A good rater is one who recognises what features of someone's English are likely to give rise to problems of intelligibility. Ideally, a rater will therefore be familiar with all the major varieties of English and will have an understanding of phonetics and phenomena such as L1 interference. The question of whether the rater is an English native speaker is immaterial; what is crucial is that he or she can consistently assess speech samples and rate them appropriately.

\section{English as a lingua franca}

In recent years the concept of English as a lingua franca (ELF) has been widely discussed (Jenkins, 2004; Seidlhofer, 2001, 2004) and hotly debated (Cogo, 2008; Saraceni, 2008). The basic ideas behind the ELF programme are straightforward:

First, speakers in Kachru's expanding circle countries (Kachru, 1989) increasingly use L2 English as a means of communication with other expanding circle L2 English speakers. Since this is the prototypical use of a language as a lingua franca, the English used in such communication should no longer be described as EFL (English as a foreign language) as this would seem to be more appropriate for L2-L1 interaction. Second, if English in expanding circle communication is now best described as a lingua franca, then inner circle (native; L1) speakers are irrelevant as far as the norms of that language are concerned, i.e. this variety of English starts to develop its own internal rules or norms and thus becomes endonormative. Now, if English is used for communicative purposes by speakers of vastly different languages around the world, will we perhaps arrive at some variety that is globally understandable? As far as the sound system of ELF is concerned, attempts have been made to identify a common phonological core which would guarantee mutual intelligibility. Jenkins (2000) first published a study of the phonology of international English which tried to distinguish between the features of English phonology that are essential to mutual intelligibility and features that are more peripheral. Essential are, for example, vowel length contrasts, nuclear stress production or aspiration of initial voiceless plosives (Jenkins, 2000:159). In other words, L2 speakers of English who use the language for international purposes with mainly other L2 speakers of English must try to get these features right and in formal English teaching every effort must be made to get students to achieve the right pronunciation, as otherwise mutual intelligibility suffers.

Thus, an Italian speaker who produces an unaspirated initial plosive in 'Pete' (because Italian plosives are not aspirated, e.g. 'Pietro') might be mistakenly understood as saying 'beat'.

Jenkins bases her proposals on empirical data of what causes misunderstandings between L2 English speakers. Her reasoning is as follows: interference from English speakers' first languages is acceptable as long as it does not result in unintelligibility. Such acceptable interference should be regarded as part of the newly developed variety of English (e.g. Euro-English; Chinese English); teachers of English should not waste any time trying to stamp out what is from the point of view of the standard language a mispronunciation. Jenkins discusses the case of interdental fricatives $([\theta],[ð])$ at 
some length. She argues that first of all, the interdental realisation of these sounds is not a feature of all English L1 varieties; thus, in Cockney English these sounds are replaced by [v] and [f], which acoustically are very similar. In some forms of Irish English the fricatives are replaced by stops. Jenkins notes that in L2 English varieties these interdental fricatives are likewise often replaced by sounds which are close to them and do occur in the speakers' first languages. Thus, in German English, [s]/[z] replace the interdental sounds. This is perhaps one of the most salient features of German English and one which is often ridiculed by native speakers. ${ }^{4}$ The author argues that such replacements cause no loss of intelligibility and are thus perfectly acceptable.

Jenkins discusses a number of additional features, e.g. clear vs. dark [1], i.e. the velar realisation of $/ 1 /$ in certain environments, or indeed the change of velar [1] to a vowel sound in words like 'bill'. Realising the phoneme /1/ either as dark or as clear variants in all positions does not affect intelligibility and thus the rule of allophonic distribution should not figure in the teaching of ELF pronunciation.

At the other end of the spectrum is the following case. As is well known, the Spanish letters $b$ and $v$ represent a bilabial, voiced stop at the beginning of an utterance, and a bilabial, voiced fricative inter-vocalically (this is a somewhat simplified description). Carrying these phonetic patterns over into English, a Spanish speaker would typically pronounce 'very' as something resembling 'berry' and 'habit' as something resembling 'have it'. This, so the argument goes, frequently leads to misunderstandings and thus the 'correct' Standard English phonetic realisation of these sounds must be insisted on (Jenkins, 2000:143).

The line of argumentation thus seems to be clear. Phonemic distinctions of standard English (StBrE, StAmE) must be maintained in expanding-circle varieties of English used for international purposes (i.e. as a lingua franca) if abandoning these distinctions results in potential misunderstandings. On the other hand, phonemic distinctions which have a low functional load and hardly ever result in misunderstandings $(/ \theta / \mathrm{vs} / \mathrm{t} /$ or $/ \mathrm{s} /$ ) or subphonemic (allophonic) distribution (dark vs. clear [1]) can be abandoned without loss in ELF. This approach would seem to me to make sense in that it posits an L1 phonological system which must be approximated by L2 English speakers to the extent that crucial distinctions and contrasts are maintained, whereas low-level allophonic details can be discarded. Despite claims to the contrary, it is obvious that this approach is in fact exonormic, as it judges the suitability of ELF in terms of permissible deviations from an L1 model. It is thus by no means endonormic.

The major problem with the common core approach is that it essentially depends on a universally existing L1 model. Traditionally, the English-learning world has mostly looked at two prestigious standard systems for guidance, Standard British English (StBrE) and Standard American English (StAmE); these two varieties are very close in terms of phonological system, though with many differences in phonetic detail. However, English has become pluricentric and not simply bicentric. Today, other L1 varieties, such as Canadian English or Antipodean English (AusE and NZE), must be factored into the equation as well (leaving aside the question of L2 standards such as Indian English). It is here that Jenkins' approach to ELF phonology seems to run into problems. As is well known, in certain forms of Antipodean English, a vowel shift is taking place which basically raises all short front vowels and centralises the highest front vowel. Thus 'bat' becomes 'bet', 'bet' becomes 'bit' and 'bit' is centralised, shifting in the vicinity of the vowel in 'but'. The centralisation of /i/ seems to be restricted to NZ, is keenly felt by Antipodean English speakers to be peculiar to $\mathrm{NZ}$, and as such is very much an indicator of NZ identity. ${ }^{5}$ This vowel change is clearly reminiscent of the first great vowel shift which produced such forms as [mais] 'mice' from an earlier [miss] (Burridge \& Mulder, 1998:86). Such drastic changes in the sound system clearly pose a great challenge for mutual intelligibility. Labov (2002) reports a similar change occurring among young Canadians. This time, however, the vowel shift is taking place in the opposite direction and seems to have been triggered by the merger of the short o ('cot') with long o ('caught'):

$$
/ \mathrm{i} / \rightarrow / \mathrm{e} / \rightarrow / \mathfrak{} / \rightarrow \text { [a] }
$$

In the Canadian case we have a vowel which 'vacated' its place and merged with another one, thereby leaving an empty space which consequently triggered a repositioning of the short front vowels, keeping the phonemic status of these latter unchanged. In the NZ case 
we simply have a realignment of the vowels without any triggering merger.

\section{Common core}

The discussion so far has dealt with only a very small part of the phonology of English but it has shown that the idea of a core component of English phonology which is common to all standard L1 varieties is unrealistic. In fact, the idea that all Englishes around the world share a common core, not only in phonology, but also in grammar or lexicon is probably misleading. As Kortmann \& Schneider put it: 'it is under discussion to what extent a "common core" actually exists: there is some degree of uniformity across the major national varieties, but once one looks into details of expression and preferences, there are also considerable differences' (2008:2). To allow for divergence and for language varieties that drift apart, not only at the periphery of the system, but also at the core, the picture of partially overlapping concentric circles is probably more apt. The major established varieties of English overlap to a considerable degree and this is why mutual intelligibility between these varieties is (still) possible, provided there is enough mutual exposure to them. It is a common phenomenon that unfamiliar dialects or accents/ pronunciations of the same language require 'tuning into'. Given enough exposure and time for this tuning process, speakers can work out correspondences, provided there is enough overlap in the vocabulary and the structures of the two varieties.

Above we have examined in some detail a small number of problematic cases which could give rise to possible misunderstandings. Let us review the most important differences between the Spanish English (SpE) case and the New Zealand English case. SpE is an L2 variety of English spoken by vast numbers of people; this variety is well-known in many parts of the world, especially in the US. NZE is an established L1 variety of English spoken by few people and little known outside the Antipodes. What are now the recommendations for speakers of these varieties when they engage in international communication, i.e. when they use English as a lingua franca? Are we going to say that speakers of NZE should back shift their vowels to bring them back in line with StBrE or StAmE? Likewise, would they have to learn to distinguish between the diphthongs in 'air' and 'ear', diphthongs which have merged for most younger speakers of NZE? ${ }^{6}$ The development of English has shown many complete mergers of previously distinct word pairs; thus, 'night' and 'knight' have merged, as have 'meat' and 'meet', to give but two examples. Their original distinctiveness is preserved in the archaic spelling of the words. Clearly, English functions quite well despite these mergers with their potential for misunderstandings. As is well known, not all dialects of English have undergone all of the sound changes of the standard language. Thus, Scottish English preserves certain phonemic differences which were lost elsewhere: 'hoarsehorse', 'pour-poor', 'which-witch'. These differences reflect an older stage of the English language vis-à-vis standard English. Now, if possible ambiguity were the yardstick of acceptability, one could argue that International English (ELF) should follow Scottish English here, which would entail a relearning for many E L1 speakers. Presumably, such a proposal would not meet with much approval. Likewise, the present author would suggest that there is no need for speakers of standard NZE to modify their vowels and indeed there is no need for speakers of 'Standard L2 Spanish English' to keep their v and b distinct. These are simply phonological features of the two English varieties. In the last section of this article I will briefly discuss the consequences of the above discussion for English as used in aviation.

\section{Which English for aviation?}

We have now seen that the 'common core' approach to English as a global lingua franca does not look promising. Where does that leave global aviation English? In aviation, as has been pointed out before, we are dealing with the use of English as a lingua franca which must be universally understandable. This is in contrast to varieties of ELF which are found in geographically restricted areas, such as in some parts of Australia where English functions as a means of communication between different aboriginal communities. Clearly, in these cases it is of no importance whether people in other parts of the world understand this variety. In terms of acceptability of ELF for aviation we are faced with a situation where some varieties are more equal than others and statements such as the following - while valid when referring to linguistic structure - are irrelevant: 'Nowadays there is a universal acknowledgement among 
sociolinguistics scholars that all varieties of English are equal' (Cogo, 2008:58). Due to its socioeconomic power, the US is by far the most important country in the world for aviation. A substantial part of the world's total pilot training programmes takes place in the US and thus it is clear that StAmE is the most prestigious variety of English in aviation. In addition to StAmE, the other major standard varieties of English such as StBrE pose no problem of acceptability, but beyond that, the situation becomes unclear. It would seem to be up to ICAO to clarify the picture and to specify exactly which Englishes it deems acceptable. What does appear clear to the present author is that varieties which are important in terms of geographic distribution (New Zealand) and/or in terms of the number of people who speak it (India) must be accepted. Once this point has been clarified, pilots and air traffic controllers can then be trained in these varieties, i.e. they can learn to tune into and understand all of these different accents/pronunciations as part of their training. English may have become the universally accepted language of aviation, but we are still a long way away from a universally agreed upon standard of English for aviation.

\section{Notes}

1 I would like to express my gratitude to Jeff Siegel for reading an earlier version of this paper and for making valuable suggestions.

2 Quoted in Hinnenkamp (1998), who provides further relevant references.

3 As is the case for Standard English, phraseology has its 'dialects'; for a British version see Civil Aviation Authority, 2008.

4 See for example John Cleese in the episode 'The Germans' of the British sitcom 'Fawlty Towers'.

5 There is a certain amount of good-natured rivalry between speakers of $\mathrm{Oz}$ and NZ English and 'this rivalry is keenly illustrated by the linguistically aware graffiti artist who upon encountering NZ SUX boldly emblazoned on a wall at Bondi Beach replied with his spray can AUSTRALIA NIL' (Cox, 1998).

6 For a recent discussion and further references, see Hay, Warren, \& Drager, 2006.

\section{References}

Burridge, K. \& Mulder, J. 1998. English in Australia and New Zealand. Oxford: University Press.

Civil Aviation Authority. 2008. Radiotelephony Manual.

Cogo, A. 2008. 'English as a Lingua Franca: form

follows function.' English Today, 24(3), 58-61.
Considine, B. 2007. 'How European air traffic controllers master English.' Online at <http://www.saa.com.sg/saa/en/About_Us/e-revie w-feb2007.html>.

Cox, J. 1998. 'Australian vowels: Australian identity.'

[Electronic Version]. Ozwords, 98. Online at $<$ http://www.anu.edu.au/andc/pubs/ozwords/Nov ember_98/6._australian_accent.htm $>$.

Crystal, D. 2004. The Stories of English. Penguin Books.

Graddol, D. 2006. English Next. Why Global English May Mean the End of 'English as a Foreign Language'. British Council.

Hay, J., Warren, P., \& Drager, K. 2006. 'Factors influencing speech perception in the context of a merger-in-progress.' Journal of Phonetics, 34(4), 458-84.

Hinnenkamp, V. 1998. 'Mißverständnisse in Gesprächen.' Online at <http://www.hochschulefulda.de/fileadmin/ Fachbereich_SK/ missv_n.htm >. (Accessed August 21, 2008)

International Civil Aviation Organization. 2004. Manual on the Implementation of ICAO Language Proficiency Requirements.

—. 2007. Manual of Radiotelephony.Unpublished manuscript.

—. 2008. Language Testing Criteria for Global Harmonization. Unpublished Circular 318-AN/180.

Jenkins, J. 2000. The Phonology of English as an International Language. Oxford: University Press.

-. 2004. ELF at the gate: the position of English as a Lingua Franca. European Messenger 13(2), 63-8.

Jones, R. K. 2003. 'Miscommunication between pilots and air traffic control.' Language Problems \& Language Planning, 27(3), 233-48.

Kachru, B. B. 1989. 'Teaching World Englishes.' Indian Journal of Applied Linguistics, 15(1), 85-95.

Kortmann, B., \& Schneider, E. W. 2008. 'General Introduction.' In K. Burridge \& B. Kortmann (eds), Varieties of English 3: The Pacific and Australasia. Berlin: Mouton de Gruyter.

Labov, W. 2002. Driving Forces in Linguistic Change. Paper presented at the International Conference on Korean Linguistics. Online at $<$ http://www.ling.upenn.edu/ wlabov/Papers/DF LC.htm $>$.

Saraceni, M. 2008. 'English as a lingua franca: between form and function.' English Today, 24(2), 20-6.

Seidlhofer, B. 2001. 'Closing a conceptual gap: the case for a description of english as a lingua franca.' International Journal of Applied Linguistics, 11(2), 133-58.

-. 2004. 'Research perspectives on teaching english as a lingua franca.' Annual Review of Applied Linguistics, 24, 209-39.

The Sydney Morning Herald. 2008. 'Crash probe looks at language barriers.' August 28.

Tajima, A. 2004. 'Fatal miscommunication: English in aviation safety.' World Englishes, 23(3), 451-70.

Urban, W. 1939. Language and Reality: the Philosophy of Language and the Principles of Symbolism. London: George Allen and Unwin. 